\title{
Evoking false beliefs about autobiographical experience
}

\author{
Alan S. Brown \\ Southern Methodist University, Dallas, Texas \\ AND \\ Elizabeth J. Marsh \\ Duke University, Durham, North Carolina
}

\begin{abstract}
In two experiments, we demonstrate that laboratory procedures can evoke false beliefs about autobiographical experience. After shallowly processing photographs of real-world locations, participants returned 1 week (Experiments 1 and 2) or 3 weeks (Experiment 2) later to evaluate whether they had actually visited each of a series of new and old pictured locations. Mundane and unique scenes from an unfamiliar college campus (Duke or SMU) were shown zero, one, or two times in the first session. Prior exposure increased participants' beliefs that they had visited locations that they had never actually visited. Furthermore, participants gave higher visit ratings to mundane than to unique scenes, and this did not vary with exposure frequency or delay. This laboratory procedure for inducing autobiographical false beliefs may have implications for better understanding various illusions of recognition.
\end{abstract}

There is an extensive literature documenting how implicit memory can influence a wide variety of cognitive behaviors, such as response fluency (Mitchell \& Brown, 1988), evaluation of fame (Jacoby, Kelley, Brown, \& Jasechko, 1989) and assessment of credibility (Brown \& Nix, 1996). Our intent in the present investigation is to expand upon this literature and examine whether implicit memory has the capacity to alter memory for remote autobiographical experiences. There have been numerous demonstrations that implicit familiarity can positively bias explicit recollection in the laboratory (Jacoby, 1999; Roediger \& McDermott, 1993), but is it also possible that a laboratory experience can create an illusion of recognition involving one's personal past? False memories for single events can be implanted, although the effects tend to be limited to a minority of participants (Hyman, Husband, \& Billings, 1995). Furthermore, these procedures often involve a strong element of coercion with explicit suggestions from trusted confederates (Loftus \& Pickrell, 1995) or by using "heavy handed" manipulations that are elaborate and time consuming (Bernstein, Whittlesea, \& Loftus, 2002).

In contrast to this, our intent is to create an illusion that a remote autobiographical experience occurred, through brief exposure rather than protracted explication. These "implanted memories" would be lacking in recollective detail yet lead participants to believe that they have actually visited a particular location. A prior study attempted to create a positive memory bias (increased confidence) for plausible autobiographical experiences, such as breaking a window while playing ball. Using the revelation effect, Bernstein et al. (2002) found that participants were more confident about having experienced hypothetical remote autobiographical events after having unscrambled a key word in the description (e.g., "broke a dwniwo playing ball").

Whereas our intent is similar to Bernstein et al.'s (2002), our procedure differs in several important respects. First, Bernstein et al. (2002) did not confirm whether participants had actually had the cued experiences, but we did verify this via questionnaire. Also, our processing manipulation occurred in a prior task, whereas Bernstein et al.'s (2002) bias manipulation (unscrambling an anagram) immediately preceded the autobiographical rating. Finally, our experiential cues were very specific (visual scenes) rather than general and schematic (winning a blue ribbon).

We examined whether prior exposure to a photograph of a specific location could later result in a sense that one had actually been there, using scenes that participants could have plausibly encountered: college campuses. To minimize explicit recollection, initial processing of the scenes was superficial, and a substantial intersession interval was used. The effects of mundane versus unique scenes, presentation frequency, and intersession interval on false belief were evaluated. We predicted that false recognition would be more likely with mundane campus photographs because they contain fewer clues to enable one to dismiss them as never visited. With respect to number of prior exposures, the evidence is ambiguous about whether implicit memory increases past one prior exposure (Brown, Jones, \& Mitchell, 1996). Finally, we hypothesized that any familiarity bias would be evident at both short and long delays because implicit memory often

A. S. Brown, abrown@smu.edu 
shows little to no decline over a period of several days (Tulving, Schacter, \& Stark, 1982), months (Cave, 1997), or years (Mitchell, 2006).

To preview, during Session 1, participants shallowly processed photos of unfamiliar campus settings and filler nature scenes. For each photograph, participants detected a cross embedded in the scene. Both mundane (settings common to many colleges) and unique shots from an unfamiliar campus were presented once or twice. Participants returned for Session 2 after an interval of 1 week (Experiments 1 and 2) or 3 weeks (Experiment 2) and evaluated whether they had ever visited each location depicted in a mixture of old and new campus scenes. In Session 2, scenes were flashed briefly to minimize use of analytic strategies, and photographs of each participant's home campus also were included to allow for both hits and false alarms.

\section{EXPERIMENT 1}

\section{Method}

Participants. The analyses included data from 78 participants - 36 from SMU and 42 from Duke. Data were excluded from participants who had participated in Session 1 but failed to return for Session 2 (7 from SMU; 3 from Duke) or who had reported having visited the target (away) campus (11 from SMU; 1 from Duke). Data from first-year undergraduates who had just arrived on campus were not included in the analyses, since both the home and the away campus photos would be unfamiliar to them. ${ }^{1}$

Materials. There were 144 critical photos ( 72 from SMU; 72 from Duke) and 192 filler photos (144 fillers in Session 1; 48 in Session 2). Half of the critical photos were mundane, and half were unique, as determined by five judges from each school who were unfamiliar with the other campus. Mundane photos depicted locations common to all campuses (libraries, classrooms, streets), whereas unique photos depicted sites distinctive to the particular campus (statues, artwork, specific edifices; see Figure 1). Categories of scenes (e.g., buildings, gardens, interiors) were equally distributed across the two campus sets.

Session 1 materials consisted of away-campus critical photos (SMU shots for Duke students; Duke shots for SMU students) plus filler photos. Of the 72 critical photos, 24 were not presented, 24 were presented once, and 24 were presented twice; the assignment of photos to conditions was counterbalanced across participants. Within each of the three presentation forms, half of the photos were unique, and half were mundane. The same filler photos were used for both groups of participants in Session 1 and included photos from a third campus (Ohio State University), grand-scale nature scenes (e.g., seashores, canyons), and travel scenes (e.g., people in a desert). As with the critical photos, half of the filler photos were shown once, and half were shown twice.

Each Session 1 photo had a $2 \times 2 \mathrm{~cm}$ cross $(+)$ embedded in one of its four quadrants. The cross quadrant was randomly determined, with the constraint that all four quadrants were equally represented within both the critical and filler sets of photos. The cross was placed at one of four locations within the quadrant, and this location remained the same for both exposures of repeated pictures. Medialab and DirectRT software was used to present the photos on the computer screen in a random order. Session 2 materials consisted of all 144 critical campus shots from both campuses plus 48 filler community photos (drawn equally from Dallas, TX, and Durham, NC). These additional fillers were included to allow sufficient opportunities to make positive "visit" responses.

Design. The study consisted of a 2 (college campus: Duke, $\mathrm{SMU}) \times 2$ (typicality of campus scene: mundane, unique) $\times 3$ (number of Session 1 presentations: 0, 1,2) mixed design, with visitation judgments in Session 2 as the dependent measure. College campus was a between-subjects variable, and scene typicality and number of presentations were manipulated within subjects.

Procedure. In Session 1, each participant was tested individually on the cross-detection task using a PC. For each photo, participants pressed one of four computer keys corresponding to the quadrant in which the cross appeared. They were told that pictures might repeat and to make their quadrant decisions as quickly as possible. Each par-

\section{Mundane Campus Photo}
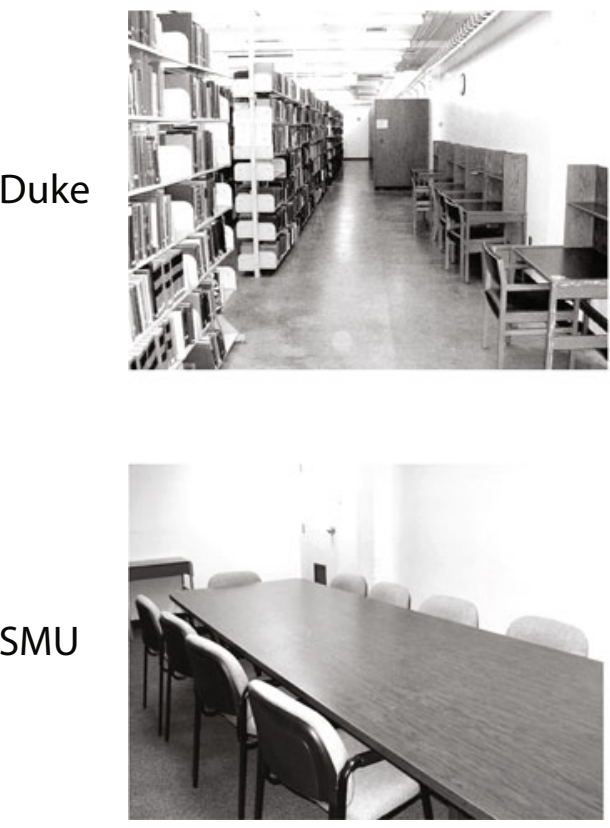

\section{Unique Campus Photo}
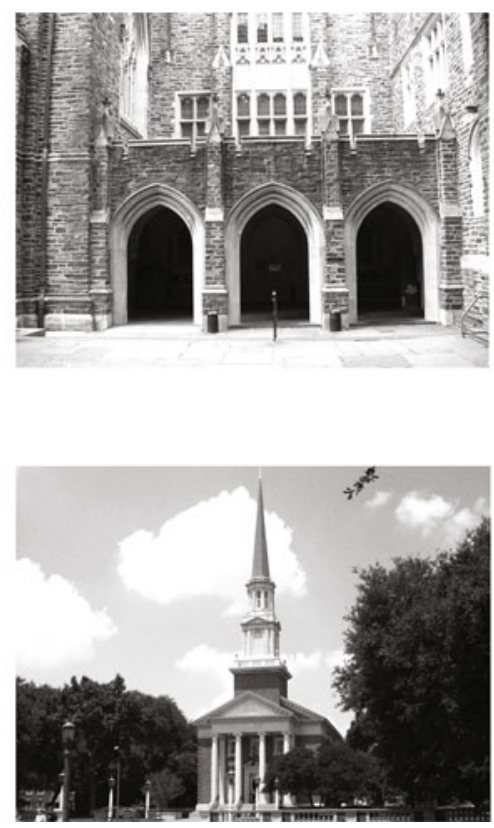

Figure 1. Examples of unique and mundane critical photos. 
ticipant saw 216 photo presentations: 48 fillers shown once, 48 fillers shown twice, 24 critical photos shown once, and 24 critical photos shown twice. Picture order was randomized, with the constraint that repeated pictures appeared once in each half of the series.

One week later, participants returned and were again tested individually on a PC. On each trial, participants pressed a key to present a scene for $500 \mathrm{msec}$ and then judged how likely they were to have visited that location in real life: $3=y e s$ (I have definitely been there before), 2 = probably (I have probably been there before), $1=$ might (I might have been there before), or $0=n o$ (I have never been there before). Following 4 practice trials (two familiar and two unfamiliar scenes, all new), the test consisted of 192 trials: 144 critical and 48 filler. Participants were told to respond as quickly as possible and that if they chose the yes option, the picture would be immediately re-presented for their rating of the vividness of their visit recollection. ${ }^{2}$ At the end of the experiment, subjects were asked whether they had visited the away campus and were probed for their awareness of the experiment's purpose before debriefing.

\section{Results and Discussion}

For all analyses, we used a .05 significance level (unless otherwise noted). A 2 (school) $\times 2$ (scene typicality) $\times 3$ (presentation number) ANOVA was computed on the mean visit ratings for other-campus scenes. There was a main effect of typicality, with higher visit ratings for mundane $(M=$ $.83)$ than unique $(M=.53)$ scenes $\left[F(1,76)=129.10, M S_{\mathrm{e}}=\right.$ $.08]$. Mean visit ratings varied significantly as a function of number of presentations in Session 1-.63 for nonpresented, .69 for once-presented, and .71 for twice-presented photos $\left[F(2,152)=5.28, M S_{\mathrm{e}}=.05\right]$. Visit ratings were significantly higher than baseline (.63) after one (.69) $[t(77)=$ $2.37, S E=.03]$ and two $(.71)[t(77)=2.99, S E=.03]$ prior exposures, with no significant difference between one and two exposures $(t<1)$. This effect of number of prior presentations did not interact with scene typicality $(F<1)$.

Duke students rated SMU scenes as more familiar $(M=.82)$ than SMU students rated Duke scenes $(M=$ .54) $\left[F(1,76)=14.92, M S_{\mathrm{e}}=.62\right]$. This result is not surprising, since Duke's gothic architecture is more atypical than SMU's red brick facades. There was a trend toward a three-way interaction $\left[F(2,152)=2.41, M S_{\mathrm{e}}=.05, p=\right.$ .093]. As shown in Table 1, there was one odd data point: SMU students' ratings dropped for mundane Duke scenes that they had previously seen twice.
As expected, visit ratings were much higher for homecampus scenes than for scenes from the never-visited campus. This was true for students from both Duke (mundane, $M=2.07, S D=.37$; unique, $M=1.96, S D=.38$ ) and SMU (mundane, $M=1.98, S D=.47$; unique, $M=1.90, S D=$ .41). The leveling of the difference between unique and mundane locations is probably due to real-life exposure.

Given the relatively small upward shift in visit ratings (see Table 1), we checked to make sure that the effect was not specific to just a few items or participants. The following data strongly suggest that this is not the case. An analysis by items replicated the significant effect of presentation frequency $\left[F(2,140)=5.94, M S_{\mathrm{e}}=.06\right]$, as well as significant differences between baseline and both one $[t(143)=2.56, S E=.03]$ and two $[t(143)=2.99, S E=$ $.03]$ prior exposures, with no significant difference between one and two exposures $(t<1)$. Furthermore, most participants gave a "yes" or "probably" visit response to at least one mundane $(87 \%)$ and one unique $(62 \%)$ picture from the away campus.

The strongest evidence of illusory autobiographical recognition is when students say that they have definitely visited the location. To evaluate this, a 2 (school) $\times 2$ (scene typicality) $\times 3$ (number of presentations) ANOVA was computed on the proportion of other-campus scenes rated yes, definitely visited. Participants were more likely to say "yes" to mundane $(10 \%)$ than to unique $(5 \%)$ scenes $\left[F(1,76)=33.48, M S_{\mathrm{e}}=.01\right]$, and this increased significantly as a function of prior presentation $[F(2,152)=$ $\left.3.83, M S_{\mathrm{e}}=.01\right]$, from $6 \%$ in the baseline condition to $8 \%$ after both one and two presentations $[t(77)=2.83, S E=$ $.008]$. This effect did not interact with school or typicality, and there was no difference between one versus two prior exposures.

In summary, Experiment 1 indicates that prior (shallow) exposure to photographs increased participants' subsequent impression that they had actually visited those locations. To our knowledge, these data represent the first successful capture of the implicit impact of a brief laboratory experience on specific, nonlaboratory, autobiographical memory. Our primary goal in Experiment 2 was to replicate these findings and extend the intersession delay out to 3 weeks.

Table 1

Mean (and $S D$ ) Visit Ratings in Session 2 As a Function of Participant Population, Delay Between Sessions, Typicality of Target Campus Photos, and Number of Presentations in the Study Phase (in Session 1)

\begin{tabular}{|c|c|c|c|c|c|c|c|c|c|c|}
\hline \multirow[b]{2}{*}{ Experiment } & \multirow[b]{2}{*}{ Participants } & \multirow{2}{*}{$\begin{array}{c}\text { Delay } \\
\text { (Weeks) }\end{array}$} & \multirow{2}{*}{$\begin{array}{c}\text { Target } \\
\text { Campus }\end{array}$} & \multirow{2}{*}{$\begin{array}{c}\text { Scene } \\
\text { Typicality }\end{array}$} & \multicolumn{2}{|c|}{ Zero } & \multicolumn{2}{|c|}{ Once } & \multicolumn{2}{|c|}{ Twice } \\
\hline & & & & & $M$ & $S D$ & $M$ & $S D$ & $M$ & $S D$ \\
\hline \multirow[t]{6}{*}{1} & Duke & 1 & SMU & Mundane & 0.94 & 0.48 & 1.03 & 0.46 & 1.09 & 0.39 \\
\hline & & 1 & SMU & Unique & 0.57 & 0.33 & 0.62 & 0.37 & 0.66 & 0.42 \\
\hline & & & & $M$ & 0.75 & 0.37 & 0.82 & 0.38 & 0.88 & 0.35 \\
\hline & SMU & 1 & Duke & Mundane & 0.64 & 0.30 & 0.68 & 0.41 & 0.60 & 0.35 \\
\hline & & 1 & Duke & Unique & 0.38 & 0.36 & 0.44 & 0.34 & 0.49 & 0.40 \\
\hline & & & & $M$ & 0.51 & 0.31 & 0.56 & 0.33 & 0.55 & 0.32 \\
\hline \multirow[t]{6}{*}{2} & SMU & 1 & Duke & Mundane & 0.68 & 0.55 & 0.67 & 0.45 & 0.66 & 0.44 \\
\hline & & 1 & Duke & Unique & 0.40 & 0.37 & 0.49 & 0.58 & 0.53 & 0.44 \\
\hline & & & & $M$ & 0.54 & 0.43 & 0.58 & 0.49 & 0.60 & 0.41 \\
\hline & & 3 & Duke & Mundane & 0.76 & 0.34 & 0.74 & 0.39 & 0.85 & 0.41 \\
\hline & & 3 & Duke & Unique & 0.44 & 0.30 & 0.48 & 0.33 & 0.55 & 0.31 \\
\hline & & & & $M$ & 0.60 & 0.27 & 0.61 & 0.31 & 0.70 & 0.33 \\
\hline
\end{tabular}




\section{EXPERIMENT 2}

\section{Method}

Participants. Given the replicability of the outcome across schools, we felt comfortable using students from one campus in Experiment 2 . Eighty-eight SMU students voluntarily participated in the study in return for extra course credit.

Materials. The 144 critical photos (72 each from SMU and Duke University) and filler photos from Experiment 1 were used again in Experiment 2. The categorization of unique and mundane critical photos was based on judges' evaluations. We reclassified unique and mundane critical photos in the following manner: Assuming that unique photos were less likely to evoke a false visit rating than mundane photos in the control (unprimed) condition, we rank-ordered SMU students' average visit ratings for Duke pictures in the 0-presentation condition in Experiment 1. Pictures were then sorted into mundane (top half) and unique (bottom half) photos, on the basis of a median split. This resulted in reclassifying 14 mundane photos as unique and 15 unique photos as mundane.

Design and Procedure. The study had a 2 (typicality of campus scene: mundane, unique) $\times 3$ (number of presentations in Session 1: 0 , $1,2) \times 2$ (delay: 1 week, 3 weeks) mixed design. This procedure replicated Experiment 1, with the exception of an intersession delay that was manipulated between participants ( 24 at 1 week; 33 at 3 weeks).

\section{Results and Discussion}

The analyses include data from 57 students. Thirty-one additional students participated but either failed to return for Session $2(n=14)$ or reported having visited Duke $(n=17)$. As in Experiment 1, an ANOVA computed on the mean visit ratings for away-campus scenes revealed significantly higher visit ratings for mundane $(M=.73)$ than for unique $(M=.48)$ scenes $[F(1,55)=68.94$, $\left.M S_{\mathrm{e}}=.07\right]$, as well as a significant effect of the number of presentations in Session $1\left[F(2,110)=3.27, M S_{\mathrm{e}}=\right.$ $.06]$. Visit ratings were significantly higher for twicepresented (.65) than for once-presented (.59) $[t(53)=$ $2.10, S E=.03]$ and nonpresented (.57) $[t(53)=2.58$, $S E=.03]$ scenes, with no difference between once- and nonpresented scenes. Replicating Experiment 1, the effect of number of presentation did not depend on whether the scenes were unique or mundane $\left[F(2,110)=1.31, M S_{\mathrm{e}}=\right.$ .05 ], and home campus visit ratings (mundane, $M=2.07$, $S D=.49$; unique, $M=1.91, S D=.42$ ) were much higher than for the away campus visits.

Visit ratings did not differ significantly between 1 and 3 weeks after Session $1(F<1)$, and delay did not interact with number of presentations $(F<1)$. Furthermore, the 3-way interaction of delay, typicality, and number of presentations was not significant $(F<1)$. As in Experiment 1 , the outcome was not specific to particular items or participants, as an analysis by items replicated the significant difference for presentation frequency $[F(2,140)=$ $\left.3.66, M S_{\mathrm{e}}=.06\right]$, with visit ratings significantly higher for twice- than for once-presented $[t(53)=2.07, S E=.03]$, and nonpresented $[t(53)=2.49, S E=.03]$ scenes, with no difference between once- and nonpresented scenes $(t<1)$. In addition, most participants gave a "yes" or "probably" visit response to at least one mundane (91\%) and one unique (70\%) away-campus scene.

The outcome was similar when we examined the proportion of away-campus scenes labeled "yes, definitely visited." "Yes" responses were more common for mun- dane scenes than unique $\left[F(1,55)=26.94, M S_{\mathrm{e}}=.006\right]$. More important, "yes" responses increased from $7.5 \%$ in the baseline condition to $8.8 \%$ after one presentation and to $9.2 \%$ after two presentations. "Yes" responses significantly increased over baseline after two prior exposures $[t(53)=$ $2.11, S E=.00]$. A linear trend analysis also yielded significance $\left[F(1,55)=4.26, M S_{\mathrm{e}}=.01\right]$. However, as was the case with the mean visit ratings, intersession interval had no impact on "yes" responses, and there was no interaction between delay and number of presentations $(F<1)$.

\section{GENERAL DISCUSSION}

In two experiments, prior shallow processing of unfamiliar locations increased individuals' beliefs that they had actually visited those places in real life. Our results add to the prior finding that laboratory procedures can bias belief in remote autobiographical experiences (Bernstein et al., 2002). Our present study strengthens this finding by verifying (via questionnaire) that the cued experience could not have actually occurred. Curiously, Bernstein, Godfrey, and Davison (2004) replicated the original Bernstein et al. (2002) finding, but discovered that prior exposure to the critical word in an earlier task had no influence on the confidence rating of the remote autobiographical experience. Perhaps this relates to the difference in the type of autobiographical events tested. Whereas ours involved a hyper-specific memory (visual scene), Bernstein et al. (2002) tested more general categories of experience (breaking a window while playing ball).

Surprisingly, prior exposure inflated visit ratings equally for mundane and unique scenes. We had hypothesized that it would be easier to induce illusory autobiographical recognition for mundane scenes, as these should contain fewer distinctive features to help disconfirm an actual visit. However, because all scenes came from college campuses, they may not have provided the strongest instantiation of such a manipulation. Furthermore, our brief, 0.5 -sec presentation at test, which was used to prevent analytical processing, may have obscured any difference between these two sets of items. That is, more viewing time might have allowed participants to identify more details, enabling them to differentially exclude more unique pictures as possibly visited.

False visit evaluations did not differ consistently as a function of whether the scene had been seen once or twice previously. This is less surprising, as the implicit memory literature is ambiguous on the impact of number of prior exposures on the magnitude of priming (Brown et al., 1996). Finally, the length of the delay (1 week or 3 weeks) had no effect on false visit reports, supporting the persistence of implicit memory over long intervals (Cave, 1997; Mitchell, 2006). This illusion of prior experience may have resulted from more fluid perceptual processing of previously viewed test scenes (Johnston, Dark, \& Jacoby, 1985), although it may also be mediated by other implicitly altered characteristics, such as enhanced positive affect (cf. Seamon, Brody, \& Kauff, 1983).

Our study relates to other findings on misattributions of implicit memories. For example, in the mere exposure effect, participants give higher liking ratings to previously 
flashed shapes, even though they do not recognize them above chance (Kunst-Wilson \& Zajonc, 1980; Whittlesea $\&$ Price, 2001), and delay has no impact (Seamon et al., 1983). In the false fame effect, prior laboratory exposure to a nonfamous name is misinterpreted as preexperimental fame after a delay (Jacoby et al., 1989).

Our outcome also relates to the déjà vu experience, where there is a stark clash between a subjective sense of familiarity and an objective evaluation of unfamiliarity (cf. Brown, 2003, 2004). One plausible interpretation of déjà $\mathrm{vu}$ is that part or all of a particular situation may actually have been previously experienced but not explicitly recollected. Jacoby and Whitehouse (1989) modeled this effect by using a list-learning procedure, where a "hasty glance" at an unstudied word prior to its presentation at full awareness biased participants to believe that it had appeared in an earlier list (cf. I. H. Bernstein \& Welch, 1991; Joordens \& Merikle, 1992). Our present investigation is similar to this design, except that we used a remote autobiographical memory rather than an episodic list-learning framework.

When asked to describe their subjective experiences, most participants volunteered that they had a sense of confusion about whether they had previously visited a target location (70\% in Experiment 1; 86\% in Experiment 2). Further evaluation of these open-ended responses (via coders) revealed that nearly half had experienced déjà vu or something very similar to it (46\% in Experiment 1; $49 \%$ in Experiment 2; cf. Brown, 2004). These data confirm that the present paradigm effectively instilled a sense of false memory, or at least a reasonable degree of uncertainty about one's personal past encounters.

In summary, we presented a method for experimentally enhancing false beliefs in remote autobiographical memory. This illusion of false positive recognition was not altered by retention interval (1 week or 3 weeks) or scene typicality (unique or mundane). While we have demonstrated that a simple prior exposure can lead to some belief that one has actually visited a location, important questions remain. What are the specific mechanisms by which false real-life familiarity can be created? Is exposure to the whole scene necessary, or only part of it? How does our outcome relate to the implantation of false autobiographical memories of entire events? Whereas Loftus and Pickrell's (1995) procedure involves a confederate who helps convince the participant, can such complex memories also be successfully implanted by mere exposure, as in the present study?

\section{AUTHOR NOTE}

We thank Elaina Pelky, Holli Sink, and Sandra Zoccoli for their help with data collection. Correspondence concerning this article should be addressed to A. S. Brown, Department of Psychology, Southern Methodist University, Dallas, TX 75275 (e-mail: abrown@smu.edu).

\section{REFERENCES}

Bernstein, D. M., Godfrey, R. D., Davison, A., \& Loftus, E. F. (2004). Conditions affecting the revelation effect for autobiographical memory. Memory \& Cognition, 32, 455-462.

Bernstein, D. M., Whittlesea, B. W. A., \& Loftus, E. F. (2002). Increasing confidence in remote autobiographical memory and general knowledge: Extensions of the revelation effect. Memory \& Cognition, 30, 432-438.

Bernstein, I. H., \& Welch, K. R. (1991). Awareness, false recognition, and the Jacoby-Whitehouse effect. Journal of Experimental Psychology: General, 120, 324-328.

Brown, A. S. (2003). A review of the déjà vu experience. Psychological Bulletin, 129, 394-413.

Brown, A. S. (2004). The déjà vu experience. New York: Psychology Press.

Brown, A. S., Jones, T. C., \& Mitchell, D. B. (1996). Single and multiple test repetition priming in implicit memory. Memory, 4, 159-173.

Brown, A. S., \& Nix, L. A. (1996). Turning lies into truths: Referential validation of falsehoods. Journal of Experimental Psychology: Learning, Memory, \& Cognition, 22, 1088-1100.

CAve, C. B. (1997). Very long-lasting priming in picture naming. Psychological Science, 8, 322-325.

Hyman, I. E., JR., Husband, T. H., \& Billings, F. J. (1995). False memories of childhood experiences. Applied Cognitive Psychology, 9, 181-197.

JACOBY, L. L. (1999). Ironic effects of repetition: Measuring age-related differences in memory. Journal of Experimental Psychology: Learning, Memory, \& Cognition, 25, 3-22.

Jacoby, L. L., Kelley, C., Brown, J., \& JasechKo, J. (1989). Becoming famous overnight: Limits on the ability to avoid unconscious influences of the past. Journal of Personality \& Social Psychology, 56, 326-338.

JACOBY, L. L., \& Whitehouse, K. (1989). An illusion of memory: False recognition influenced by unconscious perception. Journal of Experimental Psychology: General, 118, 126-135.

Johnston, W. A., Dark, V. J., \& Jacoby, L. L. (1985). Perceptual fluency and recognition judgments. Journal of Experimental Psychology: Learning, Memory, \& Cognition, 11, 3-11.

Joordens, S., \& Merikle, P. M. (1992). False recognition and perception without awareness. Memory \& Cognition, 20, 151-159.

Kunst-Wilson, W. R., \& Zajonc, R. B. (1980). Affective discrimination of stimuli that cannot be recognized. Science, 207, 557-558.

Loftus, E. F., \& Pickrell, J. E. (1995). The formation of false memories. Psychiatric Annals, 25, 720-725.

Mrtchell, D. B. (2006). Nonconscious priming after 17 years: Invulnerable implicit memory? Psychological Science, 17, 925-929.

Mitchell, D. B., \& Brown, A. S. (1988). Persistent repetition priming in picture naming and its dissociation from recognition memory. Journal of Experimental Psychology: Learning, Memory, \& Cognition, 14, 213-222.

Roediger, H. L., [III], \& McDermott, K. B. (1993). Implicit memory in normal human subjects. In F. Boller \& J. Grafman (Eds.), Handbook of neuropsychology, Vol. 8 (pp. 63-131). New York: Elsevier.

Seamon, J. G., Brody, N., \& Kauff, D. M. (1983). Affective discrimination of stimuli that are not recognized: II. Effect of delay between study and test. Bulletin of the Psychonomic Society, 21, 187-189.

Tulving, E., Schacter, D. L., \& Stark, H. A. (1982). Priming effects in word-fragment completion are independent of recognition memory. Journal of Experimental Psychology: Learning, Memory, \& Cognition, 8, 336-342.

Whittlesea, B. W. A., \& Price, J. R. (2001). Implicit/explicit memory versus analytic/nonanalytic processing: Rethinking the mere exposure effect. Memory \& Cognition, 29, 234-246.

\section{NOTES}

1. In both studies, additional participants were run who had just arrived on campus, and their data were excluded. A 2-month residency rule was imposed so that students would be familiar with home-campus photos during the test phase. The home campus can be conceptualized as a "study list," and a minimal amount of experience with the "list" is required for participants to call any of the test items "old," just as would be the case in a typical experiment using lists of words or other nonautobiographical stimuli.

2. Due to the low number of "yes" responses, vividness ratings were not analyzed.

(Manuscript received March 22, 2007; revision accepted for publication July 21, 2007.) 